ISSN 0103-9954

\title{
ANÁLISE MULTICRITERIAL NA SELEÇÃO DE BACIA HIDROGRÁFICA PARA RECUPERAÇÃO AMBIENTAL
}

\author{
WATERSHED SELECTION FOR ENVIRONMENTAL REHABILITATION USING MULTICRITERIA \\ ANALYSIS
}

\author{
Carlos Eduardo da Silva Francisco ${ }^{1}$ Ricardo Marques Coelho ${ }^{2}$ \\ Roseli Buzanelli Torres ${ }^{3}$ Samuel Fernando Adami ${ }^{4}$
}

\section{RESUMO}

A bacia do ribeirão das Anhumas, na região de Campinas, SP, encontra-se com seus mananciais poluídos e assoreados em virtude de desmatamentos e do uso e ocupação irregulares das Áreas de Preservação Permanente (APP). Com essa falta de planejamento, o regime de vazão dos cursos d'água é alterado, promovendo enchentes sistemáticas, com prejuízos materiais, além de perda de várias funções ambientais dessas APP. A recuperação ambiental de uma área degradada como essa requer um esforço abrangente, muitas vezes muldisciplinar. A análise multicriterial é uma ferramenta que permite reunir características diversas, atribuir pesos e valores a estas, auxiliando na tomada de decisão. O objetivo deste trabalho foi aplicar dois métodos de análise multicriterial para otimização da seleção de uma sub-bacia hidrográfica para estudo de recuperação ambiental em APPs dentro da bacia do ribeirão das Anhumas. Dividiu-se a bacia do ribeirão das Anhumas em sete sub-bacias com o objetivo de selecionar uma delas como bacia-piloto para o planejamento e priorização para recuperação. Foram selecionados 13 critérios de natureza ambiental para aplicação da análise multicriterial. Usaram-se os métodos de análise multicriterial de Programação por Compromisso (PC) e o da Teoria dos Jogos Cooperativos (CGT). O uso dos dois métodos de análise multicriterial, PC e CGT, bem como o tratamento dos pesos atribuídos aos critérios pela média ou pela moda, não mostraram diferença significativa para seleção de bacias prioritárias. A análise multicriterial foi efetiva na seleção de bacias hidrográficas para recuperação de APPs, permitindo o uso de vários fatores no julgamento, com flexibilidade. Apesar dessa objetividade, a interferência do tomador de decisão se mostrou importante para corrigir distorções na análise. A ordenação das bacias prioritárias para recuperação de APPs, após interferência do tomador de decisão foi $4>7>5>6>2>3>1$. Procedimentos complementares essenciais ao sucesso na análise multicriterial no contexto estudado foram evitar sobreposição conceitual de critérios, efetuar adequado julgamento de valor para os critérios e usar a experiência do tomador de decisão como complementar aos resultados obtidos com os especialistas.

Palavras-chave: Áreas de preservação permanente; ribeirão das Anhumas - Campinas; programação por compromisso; Teoria dos jogos cooperativos.

\section{ABSTRACT}

The Anhumas creek watershed, in the region of Campinas, São Paulo State, Brazil, is degraded also as a result of unplanned land use of its riparian zones, considered Permanent Preservation Areas (APP). Therefore, river flow is unstable, promoting frequent flood damages, besides the lack of several environmental functions of its APPs. Environmental recovery of a degraded area requires a comprehensive effort, often multidisciplinary. Multicriterial analysis is a tool which allows gathering a diversity of attributes of the studied subject, weighing and valuating them, helping in the decision making effort. This work aims to apply two methods of multicriteria analysis to optimize the selection of a watershed for an environmental recovery study of APPs in the Anhumas watershed. The Anhumas watershed was divided in 7 sub-basins aiming the selection of one of those to implement an environmental planning study and to establish and rank areas that should be prioritized for recovery. Thirteen environmental criteria were selected for application of multicriteria analysis using the methods of Compromise Programming (PC) and Cooperative Game Theory

1. Engenheiro Agrônomo, M.Sc. Alameda Manaus, 485, CEP 13.240-000, Jarinú (SP). carlos.f.ambiental@gmail.com

2. Engenheiro Agrônomo, Dr., Centro de Solos e Recursos Ambientais, Instituto Agronômico, Caixa Postal 28, CEP 13020-902, Campinas (SP). rmcoelho@iac.sp.gov.br

3. Bióloga, Dra ${ }^{\mathrm{a}}$, Núcleo do Jardim Botânico, Instituto Agronômico, Caixa Postal 28, CEP 13020-902, Campinas (SP). rbtorres@iac.sp.gov.br

4. Geógrafo, MSc., Centro de Solos e Recursos Ambientais, Instituto Agronômico, Caixa Postal 28, CEP 13020-902, Campinas (SP). samuel@iac.sp.gov.br

Recebido para publicação em 13/04/2006 e aceito em 10/10/2007. 
(CGT). Relevance of each criterion to the analysis was given by a questionnaire answered by specialists. Basin selection results showed no difference neither between PC and CGT nor between mean or mode used to standardize weights given by specialists. Multicriteria analysis was effective, but allowed enough flexibility for the decision maker (DM) to adjust undesired analysis distortions. After DM adjustments, the priority basins were ranked as basins $4>7>5>6>2>3>1$. Important procedures when carrying out such an analysis were to avoid conceptual overlapping among different criteria, to implement appropriate value judgment for each criterion and to use decision maker expertise to supplement weights obtained with specialists.

Keywords: Permanent preservation areas; Anhumas creek - Campinas; compromise programming; cooperative game theory.

\section{INTRODUÇÃO}

O planejamento ambiental tem como objetivo organizar uma determinada área visando ao melhor desempenho em relação à sua vocação natural. Esse ordenamento pode ser realizado pela organização dos espaços em bacias hidrográficas, consideradas unidades territoriais para implementação da Política Nacional de Recursos Hídricos ${ }^{1}$. A implementação de planejamento pode evitar o uso inadequado da terra e sua degradação. Muitas vezes, são necessários estudos detalhados em áreas-piloto, em que haja maior conhecimento destas, para então se extrapolar resultados para maiores extensões de terra com características comparáveis.

A bacia do ribeirão das Anhumas, na região de Campinas, SP, apresenta elevado grau de degradação ambiental, conseqüência da falta de planejamento da ocupação da terra, que permitiu o avanço dos núcleos urbanos e industriais, de maneira desordenada, sobre áreas rurais e de preservação permanente. Como conseqüência, problemas de alagamentos em áreas densamente ocupadas, poluição do ar, do solo e das águas, perda de diversidade biológica, habitações em áreas de risco, dentre outros, ameaçam o ambiente e a qualidade de vida da população.

Considerando-se o baixo percentual de matas ciliares existentes na Bacia, são necessárias estratégias de recuperação das áreas de preservação permanente, áreas protegidas pelo Código Florestal Brasileiro (BRASIL, 2001). Apenas 5\% da extensão dos cursos d'água da bacia do Anhumas estão cobertas com mata ciliar (TORRES et al., 2006).

Freqüentemente, a tomada de decisão em planejamento ambiental necessita de grande número de variáveis do meio físico, biológico, social e econômico, quantificáveis ou não cujas combinações podem produzir diferentes alternativas de aproveitamento. Nesse contexto, ferramentas de análise que permitam reunir características tão diversas, atribuir pesos e valores a elas, dando prioridades às diferentes opções, facilitam a tomada de decisão. A análise multicriterial é um método de análise de opções para resolução de problema que utiliza vários critérios (ZELENY, 1982). O resultado dessa análise facilita a tomada de decisão, mostrando as opções prioritárias para o objetivo considerado.

A escolha dos critérios na análise multicriterial para seleção de locais ou áreas para estudos ambientais deve ser função dos objetivos do estudo. Valente (2005) usou critérios tais como proximidade de fragmentos de maior área nuclear, da cobertura florestal, da rede hidrográfica, dos centros urbanos e da malha viária, bem como vulnerabilidade à erosão, para definir áreas prioritárias para a conservação florestal em uma bacia hidrográfica e incrementar a biodiversidade regional. Por sua vez, fertilidade do solo, vegetação nativa, corpos d'água, declividade e susceptibilidade à erosão foram os critérios usados por Ferraz et al. (2003) para determinar áreas para recomposição florestal com espécies nativas em áreas de reflorestamentos homogêneos.

Existe um grande número de métodos multicriteriais para auxílio à tomada de decisão, que representam diferentes formas de aproximação para a tomada de decisão. A seleção do método depende do problema particular considerado, das preferências do tomador de decisão e de muitos outros fatores. Zuffo et al. (2002) testaram cinco métodos de análise multicriterial para auxílio à tomada de decisão em planejamento de recursos hídricos: método da Programação por Compromisso, método da Teoria dos Jogos Cooperativos;

\footnotetext{
${ }^{1}$ Lei Federal 9433/97 art. 1º, inciso V - Política Nacional de Recursos Hídricos
} 
método Analítico Hierárquico e outros dois métodos baseados nas relações hierárquicas (Electre II e Promethee II). Foram incorporados à análise vinte critérios técnicos, econômicos, sociais e ambientais. Dentre nove opções de tomada de decisão examinadas, os cinco métodos apontaram para a mesma opção ideal, e quatro deles também coincidiram na indicação de uma segunda opção, mostrando a adequabilidade da utilização de diferentes técnicas de análise multicriterial na tomada de decisão em projetos de caráter ambiental. Apesar de conferirem pequenas diferenças aos resultados, a utilização de diferentes cenários de pesos pelos autores, obtidos com o uso de diferentes medidas de tendência central, manteve as cinco opções mais parecidas e de melhor proposta tecnológica entre as melhores classificadas.

O objetivo deste trabalho foi aplicar dois métodos de análise multicriterial para seleção, dentro da bacia do ribeirão das Anhumas, de uma sub-bacia mais adequada para estudo de recuperação ambiental em APP.

\section{MATERIAL E MÉTODOS}

\section{A bacia do ribeirão das Anhumas}

A bacia hidrográfica do ribeirão das Anhumas está delimitada pelas coordenadas UTM, zona 23, de 7.462.827 m a 7.482.500 m N e de $282.500 \mathrm{~m}$ a $296.870 \mathrm{~m}$ E, correspondendo a uma superfície de 15.024,82 ha, aproximadamente $150 \mathrm{~km}^{2}$. Tem sua maior parte inserida no município de Campinas e uma pequena parte no município de Paulínia (TORRES et al., 2006), onde o ribeirão deságua no rio Atibaia.

A bacia do ribeirão das Anhumas situa-se na Depressão Periférica Paulista, em relevo de colinas médias e amplas, que tende a relevo de morrotes mais ao leste e sudeste, na transição com o Planalto Atlântico. Ao longo da bacia, as planícies aluvionais apresentam, com raras exceções, superfícies reduzidas (INSTITUTO GEOLÓGICO, 1993).

A geologia predominante na bacia, segundo Instituto Geológico (1993) é de gnaisses a leste, centroleste e sudeste; diabásios no centro-oeste; e sedimentos de idade carbonífera-permiana, constituídos por ritmitos, diamictitos e arenitos, nas porções norte e central da bacia. Com menor extensão são encontrados granitos na porção oeste e sedimentos aluviais de idade quaternária ao longo de toda a bacia, que aumentam de extensão nas áreas mais a jusante (norte).

A distribuição pluvial segue o regime típico das zonas tropicais de baixa altitude, ou seja, verão chuvoso e inverno seco. Temperatura média mínima inferior a $18^{\circ} \mathrm{C}$ durante o inverno e média máxima superior a $24^{\circ} \mathrm{C}$ no verão, sendo julho o mês mais frio $\left(12,2^{\circ} \mathrm{C}\right)$ e janeiro $\left(29,9^{\circ} \mathrm{C}\right)$ o mais quente (CEPAGRI, 2006), permitem identificar o clima, no sistema de Köppen, como Cwa, mesotérmico de inverno seco.

Os solos da bacia do ribeirão das Anhumas (TORRES et al., 2006) estão em cinco ordens do Sistema Brasileiro de Classificação de Solos (EMBRAPA, 1999): Latossolos, Argissolos, Gleissolos, Nitossolos e Neossolos. Latossolos e Argissolos ocupam proporções equivalentes na bacia, com mais de $90 \%$ da bacia. Os primeiros predominam no norte e oeste, e os Argissolos no sul e leste da bacia. Gleissolos ocorrem nas restritas planícies aluvionais, que têm maiores extensões nos trechos mais a jusante (mais ao norte da bacia). Nitossolos e Neossolos ocorrem de maneira restrita, em associações com outras classes de solo.

A superfície da bacia do ribeirão das Anhumas está impermeabilizada em cerca de $46 \%$ de sua extensão, sendo o restante ocupado com pastagens e regeneração natural (28 \%), culturas anuais e perenes (16\%), matas (3\%), reflorestamento (1,4\%) e demais usos (5,6\%) (Projeto Anhumas, 2006 (Torres et al.,2006). A vegetação atual da bacia, hoje restrita a alguns remanescentes que ocupam cerca de $2,6 \%$ da área, constitui-se por floresta estacional semidecidual, cerrado, floresta paludosa e resquícios de matas ciliares (KRONKA et al., 2005).

\section{As sub-bacias hidrográficas}

A bacia do ribeirão das Anhumas foi dividida em sete sub-bacias (Figura 1), partindo-se inicialmente na divisão adotada por Campinas (2005) que dividiu esta em seis sub-bacias. Os critérios utilizados para separação adicional de mais uma sub-bacia foram divisor topográfico de águas e limites das áreas urbanizadas. A Tabela 1 apresenta as principais características do meio físico-biótico dessas sub-bacias, doravante chamadas também de bacias, por se constituírem em bacias hidrográficas independentes. Exceção se faz à bacia 7 (ribeirão das Pedras), que engloba parte do baixo curso do ribeirão das Anhumas. 


\section{Critérios para seleção de bacia hidrográfica}

Para seleção das bacias hidrográficas, levaram-se em consideração 13 critérios, descritos abaixo, considerados relevantes por serem indicadores dos aspectos representatividade, fragilidade, contribuição ao regime das águas e potencial para recuperação das bacias.

Área da Bacia é um critério correlacionado com a possibilidade de maior diversidade de usos, entre outras funções, todas importantes para produção e regularização do regime de águas na bacia. O critério pressupõe que, quanto maior a área, maior é a importância (prioridade) da bacia. O mapa-base para o cálculo do critério foi a carta planialtimétrica 1:10.000 do IGC.

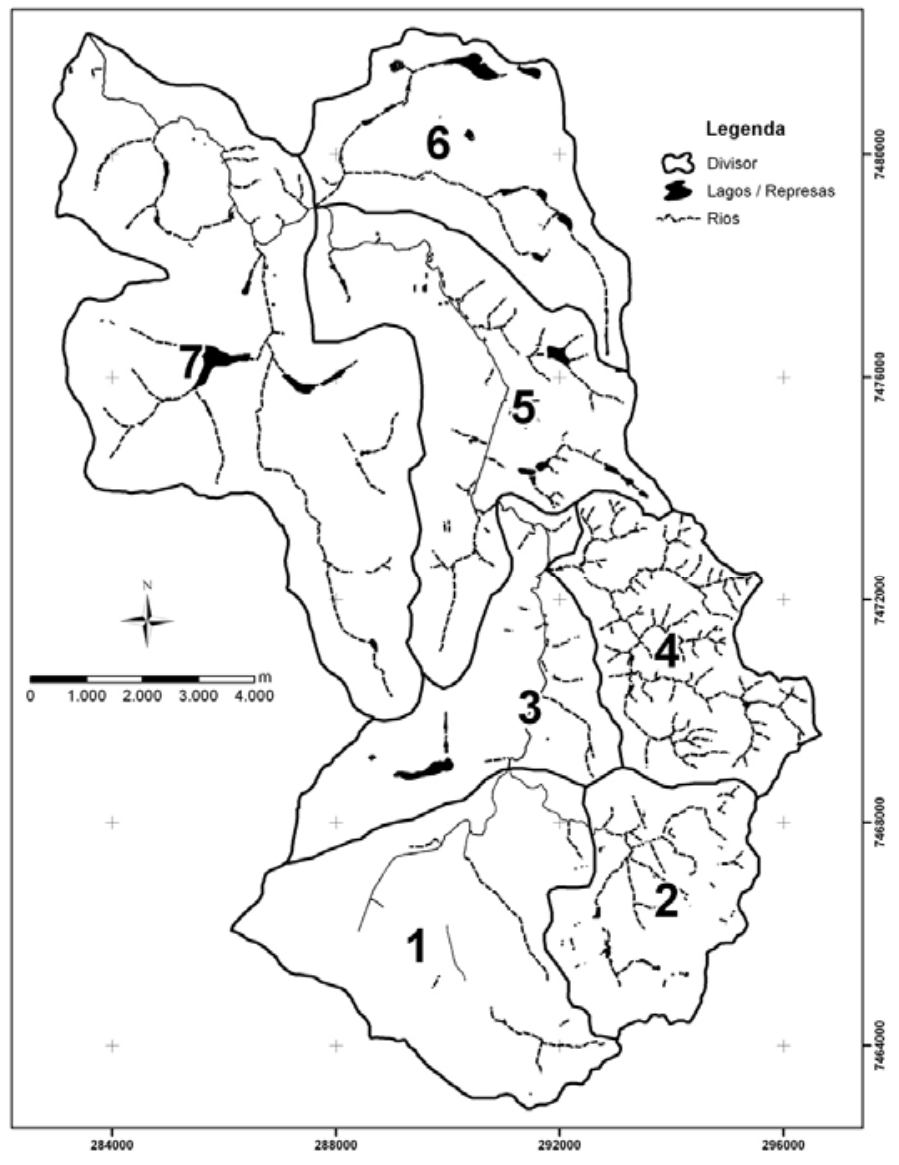

FIGURA 1: Bacia do ribeirão das Anhumas e sub-bacias (1. Alto Anhumas, 2. Córrego do Mato Dentro, 3. Médio Anhumas, 4. Córrego São Quirino, 5. Baixo-Médio Anhumas, 6. Ribeirão Monte D’Este e 7. Ribeirão das Pedras e Baixo Anhumas)

FIGURE 1: Anhumas creek watershed and its subasins (1. Upper Anhumas, 2. Mato Dentro Creek, 3. Middle Anhumas, 4. São Quirino Creek, 5. Lower-Middle Anhumas, 6. Monte D’Este Creek, 7. Das Pedras Creek and Lower Anhumas.)

Urbanização da Bacia está correlacionada com o aumento da impermeabilização do solo e tubulação dos cursos d'água, com diminuição significativa da área útil das APP. Deu-se prioridade para as bacias com menor grau de edificação ou maior proporção de atividades agrosilvopastoris. A urbanização foi quantificada a partir dos dados de uso e cobertura do solo do Projeto Anhumas (Torres et al., 2006) em SIG, baseados em fotos aéreas (ano 2001) e do sensor CCD/CBERS (ano 2006).

Áreas Com Risco de Inundação refletem o tipo de relevo da bacia e a cobertura do solo. Um elevado grau de impermeabilização da bacia aumenta drasticamente sua vazão de pico nos períodos de chuva, tornando-os mais intensos e mais rápidos. Quanto maior a extensão linear de pontos de enchente em uma bacia, maior será a prioridade para seleção dessa bacia para recuperação. Os dados de áreas com risco de inundação foram tirados de Briguenti (2005). 
Classes de Capacidade de Uso das Terras foram obtidas mediante combinação das unidades de mapeamento de solos (Torres et al., 2006) com as classes de declive, utilizando-se caracterização proposta por Lepsch et al. (1983) que divide essas classes de I a VIII conforme características de solo, água e erosão. Negligenciou-se o clima, considerado homogêneo para toda a bacia do Anhumas.

O critério Corredores de Vegetação considera que a APP com vegetação nativa melhora as condições ambientais, contribuindo com mais área verde e de lazer, maior infiltração da água e favorecendo a amenização da temperatura. Foi dada prioridade para a seleção daquelas bacias com APP com menor uso urbanizado, áreas passíveis de recuperação e para aquelas com projetos de parques lineares instituídos pelo Poder Público. Usaram-se os planos de informação Uso e Ocupação do Solo e de Hidrografia (TORRES et al. 2006) e de Santin (1999).

Densidade de Cursos d’Água é um critério que, em associação com a área da bacia, contribui na identificação da capacidade de produção de água. Esse critério identifica a bacia com maior proporção de APP a ser recuperada por área total, já que grande parte das APP está ao longo de cursos d'água ou em suas nascentes. Esse critério foi definido como a razão entre o comprimento total dos canais $(\mathrm{km})$ e a área da bacia hidrográfica $\left(\mathrm{km}^{2}\right)$. A mensuração da extensão linear de cursos d'água de cada bacia foi obtido em ambiente SIG utilizando-se do plano de informação hidrografia.

Vazão média, segundo Tucci (1993), permite avaliar os limites superiores do uso da água de um manancial para as diferentes finalidades. A vazão média $\left(\mathrm{m}^{3} / \mathrm{s}\right)$ foi estimada pela área e pelas coordenadas geográficas da bacia pelo método de regionalização hidrológica utilizado pelo Departamento de Água e Energia Elétrica do estado de São Paulo (DAEE-SP), de acordo com SÃO PAULO (2005). O critério prevê que bacias com maior vazão possuem maior prioridade para o estudo, porque teoricamente estas têm maior potencial de produção de água.

Matas ciliares refletem a função ambiental das APPs de preservar os recursos hídricos, a paisagem, a estabilidade geológica, a biodiversidade, o fluxo gênico da fauna e flora e proteger o solo (BRASIL, 2001). Tal critério estabelece que, quanto menor a extensão de cursos d'água coberta com matas ciliares na subbacia, maior a importância para recuperação e, assim, a prioridade para seleção da sub-bacia. Isso visa ao aumento de APPs recuperadas com mata ciliar, reduzindo sua fragilidade. Os dados de extensão linear de matas ciliares existentes nas sub-bacias foram obtidos do estudo da vegetação remanescente do município de Campinas (SANTIN, 1999; TORRES et al., 2006).

Diversidade de Formações Florestais, bem como a distribuição natural dessas formações em uma bacia e a possibilidade de conectividade entre os fragmentos são características importantes para o aumento do fluxo gênico entre as espécies, pela dispersão de sementes e do intercâmbio de pólen (KAGEYAMA et al., 2003), e devem ter alta prioridade para seleção de uma bacia para recuperação. Na bacia do ribeirão das Anhumas foram identificados três tipos diferentes de formações vegetais: floresta estacional semidecidual (incluindo trechos de matas ciliares), floresta paludosa e cerrado (TORRES et al. 2006). O número de fragmentos dessas formações nas bacias estudadas foi considerado para aplicação do critério.

Unidades de Conservação (UC) são previstas pela legislação, que prevê uma proteção em seu entorno por meio da criação de um buffer que possibilita a conectividade dessas unidades com as formações naturais remanescentes e com as matas ciliares adjacentes, tornando as UCs áreas diferenciadas. A existência dessas unidades distribuídas na bacia pressupõe uma maior prioridade para seleção da sub-bacia visando à sua recuperação. As UCs foram identificadas na bacia conforme Santin (1999) e São Paulo (2000).

Maior distância da sub-bacia à foz pode contribuir para a diminuição de enxurrada, fazendo a água infiltrar no solo, regulando mais a vazão do curso d'água que bacias mais à jusante. Isto é favorecido se essa sub-bacia também possuir baixa taxa de impermeabilização. O critério é a medida linear $(\mathrm{km})$ do ponto de desague da bacia no Anhumas, ao longo da drenagem, até a foz do Anhumas no rio Atibaia. 
TABELA 1: Caracterização das sub-bacias do ribeirão das Anhumas.

TABLE 1: Anhumas subasins characterization.

\begin{tabular}{|c|c|c|c|c|c|c|c|c|c|}
\hline \multirow{2}{*}{\multicolumn{3}{|c|}{ Car }} & \multicolumn{7}{|c|}{ Sub-bacias do ribeirão das Anhumas ${ }^{1}$} \\
\hline & & & 1 & 2 & 3 & 4 & 5 & 6 & 7 \\
\hline \multicolumn{3}{|c|}{ Área da bacia $\left(\mathrm{km}^{2}\right)$} & 23,76 & 12,67 & 15,16 & 14,82 & 23,81 & 17,15 & 42,70 \\
\hline \multirow{2}{*}{ Mata ciliar $^{2}$} & Extensão tc & o manancial (km) & 34,17 & 37,59 & 21,78 & 45,62 & 35,39 & 16,83 & 52,45 \\
\hline & Extensão c & $\mathrm{FN}(\mathrm{m})$ & 0 & 0 & 0 & 0 & 236 & 1800 & 610 \\
\hline \multirow{8}{*}{$\begin{array}{l}\text { Formações } \\
\text { vegetais } \\
\text { nativas: } \\
\text { quantidade } \\
\text { e área }{ }^{2}\end{array}$} & floresta & número & 4 & 1 & 4 & 3 & 7 & 2 & 10 \\
\hline & estacional & área (ha) & 17,15 & 3,46 & 13,47 & 29,23 & 22,46 & 20,50 & 103,93 \\
\hline & floresta & número & 0 & 0 & 0 & 0 & 0 & 4 & 3 \\
\hline & paludosa & área (ha) & 0 & 0 & 0 & 0 & 0 & 13,30 & 4,66 \\
\hline & cerrado & número & 0 & 0 & 0 & 0 & 1 & 0 & 0 \\
\hline & & área (ha) & 0 & 0 & 0 & 0 & 8,60 & 0 & 0 \\
\hline & $\overline{\text { total }}$ & número & 4 & 1 & 4 & 3 & 8 & 6 & 13 \\
\hline & & área (ha) & 17,15 & 3,46 & 13,47 & 29,23 & 31,06 & 33,80 & 108,59 \\
\hline \multicolumn{3}{|c|}{ Densidade relativa de fragmentos $^{3}(\%)$} & 0,017 & 0,008 & 0,026 & 0,020 & 0,033 & 0,035 & 0,030 \\
\hline \multicolumn{3}{|c|}{ Diversidade de formação de vegetação nativa } & 1 & 1 & 1 & 1 & 2 & 2 & 2 \\
\hline \multicolumn{3}{|c|}{ Grau de urbanização (\%) } & 90 & 60 & 72 & 4,8 & 35 & 14 & 38 \\
\hline \multicolumn{3}{|c|}{ Presença de Unidades de Conservação ${ }^{4}$} & $\operatorname{sim}$ & $\operatorname{sim}$ & $\operatorname{sim}$ & não & não & não & $\operatorname{sim}$ \\
\hline \multicolumn{3}{|c|}{ Extensão de pontos com enchentes ${ }^{5}(\mathrm{~km})$} & 4,10 & 4,10 & 4,20 & 1,10 & 2,20 & 0,00 & 14,00 \\
\hline \multicolumn{3}{|c|}{ Solo predominante ${ }^{6}$} & $\begin{array}{c}\mathrm{P}- \\
\mathrm{m} / \arg \end{array}$ & $\begin{array}{c}\mathrm{P}- \\
\mathrm{m} / \mathrm{arg}\end{array}$ & $\begin{array}{c}\mathrm{P}- \\
\mathrm{m} / \arg \end{array}$ & $\begin{array}{c}\mathrm{P}- \\
\mathrm{m} / \mathrm{arg}\end{array}$ & $\begin{array}{l}\mathrm{P}-\operatorname{are} / \mathrm{m} \\
\mathrm{L}-\arg \end{array}$ & $\begin{array}{c}\mathrm{L}- \\
\mathrm{m} / \arg \end{array}$ & $\begin{array}{l}\mathrm{L}- \\
\arg \end{array}$ \\
\hline \multicolumn{3}{|c|}{ Fragmentação de vegetação nativa $^{7}$} & 1,68 & 0,69 & 2,63 & 2,02 & 3,64 & 4,08 & 3,09 \\
\hline \multicolumn{3}{|c|}{ Relevo predominante $^{8}$} & cma & cpm & са & $\mathrm{cm}$ & $\begin{array}{c}\text { ca } \\
\text { cma } \\
\text { pf }\end{array}$ & са & $\begin{array}{c}\text { ca } \\
\text { cma } \\
\text { pf }\end{array}$ \\
\hline \multicolumn{3}{|c|}{ Corredor de vegetação $^{9}$} & não & não & não & $\operatorname{sim}$ & $\operatorname{sim}$ & $\operatorname{sim}$ & $\operatorname{sim}$ \\
\hline \multicolumn{3}{|c|}{ Densidade relativa de cursos d’água $\left(\mathrm{km} / \mathrm{km}^{2}\right)$} & 1,44 & 2,97 & 1,44 & 3,08 & 1,49 & 0,98 & 1,23 \\
\hline \multicolumn{3}{|c|}{ Classe de declividade predominante (\%) } & $6-9$ & $12-15$ & $6-12$ & $6-12$ & $6-12$ & $3-6$ & $6-12$ \\
\hline \multicolumn{3}{|c|}{ Classe de Capacidade de Uso } & III & III & III & III & III & III & III \\
\hline \multicolumn{3}{|c|}{ Vazão média (m³/s) } & 0,23 & 0,12 & 0,15 & 0,15 & 0,25 & 0,17 & 0,40 \\
\hline \multicolumn{3}{|c|}{ Distância da sub-bacia até a foz $(\mathrm{km})$} & 19,67 & 21,56 & 14,74 & 15,85 & 6,43 & 6,43 & 0 \\
\hline
\end{tabular}

Em que: RFN = remanescente florestal nativo; (1) = denominação das sub-bacias do Anhumas: 1 - Alto Anhumas, 2 Córrego do Mato Dentro, 3 - Médio Anhumas, 4 - Córrego São Quirino, 5 - Baixo-Médio Anhumas, 6 - Ribeirão Monte D’Este e 7 - Ribeirão das Pedras e Baixo Anhumas; $\left({ }^{2}\right)$ Torres et al., 2006; $\left({ }^{3}\right)$ Densidade relativa de fragmentos com vegetação nativa: área fragmentos $\left(\mathrm{km}^{2}\right) /$ área sub-bacia $\left(\mathrm{km}^{2}\right)$; (4) Denominação das UC e sua localização em relação às sub-bacias: 1 - Bosque dos Jequitibás, Bosque São José, Bosque dos Alemães, Bosque dos Italianos; 2 Parque Ecológico Monsenhor Emílio José Salim; 3 - Bosque da Paz; Bosque Chico Mendes, Parque Taquaral; 7 Mata de Santa Genebra (ARIE) e Parque Ecológico Hermógenes de Freitas Leitão Filho (Torres et al., 2006); (5) Método booleano (Briguenti, 2005); ( ${ }^{6}$ ) Ordem de solo: L - Latossolo, P - Argissolo; textura do solo: arg - argilosa; $\mathrm{m}$ - média; are - arenosa; (7) (Número de fragmentos/área da bacia, $\left.\mathrm{km}^{2}\right)^{*} 10 \mathrm{~km}^{2}$; $\left({ }^{8}\right.$ ) Tipos de relevo: ca (colinas amplas), pf (planícies fluviais), cma (colinas médias e amplas), cpm (colinas pequenas e morrotes), cm (Colinas e morrotes); $\left({ }^{9}\right)$ Expressa (a) possibilidade de conectividade entre os fragmentos florestais na APP e (b) existência de parques lineares instituídos pelo Poder Público municipal.

Densidade de vegetação nativa representa a proporção de vegetação nativa em relação à área total de cada bacia. Quanto maior a densidade de vegetação nativa, maior será a probalilidade de permeabilidade da matriz e conectividade da paisagem, e mais propícias serão as condições para recuperação da área (METZGER, 2003). Desse modo, quanto maior a densidade de vegetação nativa na bacia hidrográfica, maior será sua importância para recuperação.

Fragmentação da vegetação nativa representa a distribuição dos fragmentos remanescentes dentro da bacia. Quanto maior a quantidade de fragmentos dispersos, maior a probabilidade de servirem de trampolim ecológico (CULLEN et al., 2003) para a fauna dispersar sementes. O critério representa a quantidade de fragmentos florestais por $10 \mathrm{~km}^{2}$. Quanto maior seu valor, maior a probabillidade de conectividade entre os fragmentos e mais prioritária é a bacia. 


\section{Métodos de análise multicriterial}

Para a seleção de uma entre as diversas sub-bacias da bacia do ribeirão das Anhumas para o estudo de recuperação ambiental, usou-se uma metodologia que considerou vários critérios envolvidos nesse julgamento. Por isso, adotou-se a análise multicriterial, em que foram aplicados dois métodos da família da "Programação Matemática Multiobjetivo" (PARDALOS et al., 1995): o método da Programação Por Compromisso e o da Teoria dos Jogos Cooperativos. Ambos os métodos fazem uma ponderação de cada critério, que diz respeito à importância do critério para o objetivo desejado.

\section{Pesos dos critérios}

A ponderação do critério na análise multicriterial é dada pelo seu peso. Para estimativa dos pesos dos critérios foi enviada uma mensagem eletrônica com um resumo do projeto e um questionário a ser preenchido para atribuição de pesos (escala de 1 a 10) a especialistas, profissionais de diferentes áreas de interesse (Geoprocessamento, Conservação do Solo, Recursos Naturais), com experiência no estudo e diagnóstico em bacias hidrográficas. Dos dez questionários enviados, cinco foram respondidos.

Para aplicação dos métodos, as pontuações obtidas para cada critério foram agrupadas em uma matriz multicritério (matriz "payoff”). Os pesos correspondem à moda e à média expurgada dos pesos atribuídos pelos especialistas a cada critério. A média expurgada relaciona-se à média dos pesos que satisfizeram a condição:

$$
\bar{x}-s \leq \alpha_{i} \leq \bar{x}+s
$$

Em que: $\bar{X}$ = média de todos os pesos finais; $s$ = desvio-padrão; $\alpha_{i}=$ peso sugerido pelos especialistas.

Após esse tratamento estatístico, o peso foi normalizado em uma escala de 0 a 1 , dividindo-se o peso pelo somatório dos pesos de todos os critérios.

\section{Valoração dos critérios}

Os valores atribuídos aos critérios variam de 1 a 9 e são proporcionais ao resultado da implementação desse critério dentro de cada bacia hidrográfica. Assim, por exemplo, supondo que o critério vazão média varie de 0,10 a $0,50 \mathrm{~m}^{3} / \mathrm{s}$, uma bacia com vazão média de $0,32 \mathrm{~m}^{3} / \mathrm{s}$ (resultado implementado) recebe valor 5 , enquanto que outra bacia com vazão média $0,47 \mathrm{~m}^{3} / \mathrm{s}$ (resultado implementado) recebe valor 9. A amplitude das classes do resultado implementado para cada critério é, de certa maneira, flexível. Isso permite produzir classes que atendam às necessidades da análise sem, contudo, comprometer os resultados ou estabelecer tendências. Essa flexibilidade foi exercida nesta análise em alguns critérios, na qual houve necessidade de ajustar-se a amplitude das classes.

\section{Método Programação de Compromisso (PC)}

Esse método se baseia no conceito de distância métrica entre dois pontos cujas coordenadas são conhecidas (ZELENY, 1982). O método procura minimizar a distância de todos os pontos possíveis de ocorrerem em relação a um determinado ponto identificado pelo tomador de decisão (DM), o "ponto meta". O tomador de decisão estipula valores para os critérios de julgamento, variando em uma escala de 1 a 9 , como explicado anteriormente, baseado na aplicação do critério para cada opção ou cenário considerado. A distância métrica é dada pela equação a seguir, baseada em Zuffo et al. (2002):

$$
l_{s}(x)=\left(\sum_{i=1}^{n} \alpha_{i}^{S}\left|\frac{f_{i}^{*}-f(x)}{f_{i}^{*}-f_{i, w}}\right|^{S}\right)^{1 / s}
$$

Em que: $l_{s}(x)=$ distância entre a solução obtida com o procedimento metodológico $x$ e a solução ideal; $\alpha_{i}=$ peso atribuído a cada critério i; $f_{i, w}=$ pior valor obtido para o critério i: $f_{i}^{*}=$ melhor valor obtido para o critério i; $f_{i}(x)=$ resultado da implementação da decisão x considerando o critério i; $S=$ proporcionalidade aplicada aos desvios, sendo $1 \leq S \leq \infty$; neste trabalho foi escolhido o valor $S=1$, de forma a manter todos os desvios de $f_{i}^{*}$ 
proporcionais às suas magnitudes.

\section{Método da Teoria dos Jogos Cooperativos (CGT)}

No método da Teoria dos Jogos Cooperativos, ao contrário do método PC, a solução ideal é aquela que maximiza a distância de um determinado ponto de nível mínimo, no qual a medida de distância utilizada é a geométrica (Gershon \& Duckstein, 1983). A função da distância $l_{s}(\mathrm{x})$ utilizada é dada por:

$$
l_{s}(x)=\prod_{i=1}^{n}\left|f(x)-f_{i}^{*}\right|^{\alpha_{i}}
$$

Em que: $l_{s}(x)$ = distância entre a solução obtida com o procedimento metodológico $x$ e a solução ideal; $f_{i}(x)$ = resultado da implementação da decisão x considerando o critério i; $f_{i}^{*}=$ menor valor obtido para o critério i; $\alpha_{i}=$ peso atribuído a cada critério i.

\section{RESULTADOS E DISCUSSÃO}

Os fatores, aqui chamados de critérios, que influem na escolha de uma bacia para o estudo de recuperação podem ser analisados por meio de métodos de análise multicriterial. Essa análise permite atribuir importância distinta para cada fator, por meio dos pesos, bem como quantificar o valor de cada fator em uma determinada bacia.

\section{Pesos e Matriz Pay-Off}

Dos 16 critérios apresentados aos especialistas no questionário, três deles não foram usados na análise das respostas aos questionários: Quantidade de Fragmentos Florestais (QFF), Grau de Degradação (GD) e Declividade Média (DeclM). QFF foi eliminado por ser combinação dos critérios Fragmentação da Vegetação Nativa e Área da Bacia, DeclM por estar implícito no critério Classe de Capacidade de Uso e GD foi eliminado da análise for falta de informações precisas, no momento da análise, para seu julgamento.

Tomando-se como referência o desvio-padrão 2, que representa 20\% do máximo (peso 10) de peso atribuível pelos especialistas, observa-se que seis dos 13 critérios tiveram desvios-padrão maiores que 2 (Tabela 2). Desvios elevados significam diferenças de opinião entre os especialistas em relação ao critério. O caso mais marcante foi em relação ao critério Grau de Urbanização, no qual um dos especialistas atribuiu peso 1, enquanto que os outros atribuíram pesos 8 ou 10. Pode-se interpretar essa diferença a uma interpretação incorreta do critério ou ao seu não-entendimento pelo especialista. Casos como esse chamam a atenção do tomador de decisão, sugerindo a necessidade de sua interferência. O uso da média expurgada, como descrito nos métodos deste trabalho, reduz as variações nas opiniões dos especialistas, reduzindo os desvios. O uso da média expurgada, contudo, não atenua efeitos relativos a uma possível interpretação equivocada do critério pelos especialistas. Nesse momento, a experiência do tomador de decisão é importante - e deve ser utilizada - para realizar esse julgamento, já que não necessariamente a maioria (das respostas dos especialistas) estará correta. Nessa flexibilidade reside uma vantagem do método de análise multicriterial (ZUFFO, 2002)

Distância da Sub-bacia à Foz do Anhumas, Grau de Urbanização, Corredores de Vegetação e Áreas de Risco de Inundação foram os critérios que obtiveram maiores pesos (Tabela 3). Por outro lado, Área da Bacia foi o critério com menores pesos. Mesmo não tendo sido dada a opção aos especialistas de eliminação de critérios, entende-se que o peso 1 atribuído por dois especialistas ao critério Área da Bacia, bem como o valor baixo atribuído pelos demais especialistas a esse critério, reflete sua baixa importância. A inclusão desse critério no questionário, bem como o estabelecimento de proporcionalidade direta entre o peso e o tamanho da bacia (maior a área, maior a importância), foi feita considerando-se que em bacias de maior extensão aumentar-se-ia a probabilidade de ocorrência de fatores desejáveis, tais como maior diversidade de usos não-urbanos. Todavia, essa interpretação dos especialistas nos pareceu acertada, já que nas maiores bacias aumenta a probabilidade não só da ocorrência de condições desejáveis, como também daquelas não desejáveis. Assim, isoladamente, área pode realmente ser considerada um critério pouco relevante. Para os demais critérios, considerou-se que as respostas obtidas corresponderam ao conhecimento dos especialistas no assunto e são, portanto, válidas para a análise. 
TABELA 2: Pesos obtidos pelos questionários (pesos não-normalizados) para cada critério e sua moda, média, desvio-padrão e média expurgada.

TABLE 2: Weights obtained with the questionnaire (not standardized) for each criterion, with their mode, mean, standard deviation and purged mean.

\begin{tabular}{|c|c|c|c|c|c|c|c|c|c|}
\hline \multirow{2}{*}{ Critérios } & \multicolumn{5}{|c|}{ Especialistas } & \multirow{2}{*}{ Moda } & \multirow{2}{*}{ Média } & \multirow{2}{*}{$\begin{array}{c}\text { Desvio } \\
\text { padrão (s) }\end{array}$} & \multirow{2}{*}{ Média expurgada } \\
\hline & 1 & 2 & 3 & 4 & 5 & & & & \\
\hline Área da bacia & 3 & 1 & 1 & 6 & 4 & 1 & 3 & 2,12 & 2,25 \\
\hline Grau de urbanização & 10 & 1 & 8 & 10 & 10 & 10 & 7,8 & 3,90 & 9,50 \\
\hline Área de risco de inundação & 8 & 9 & 9 & 6 & 8 & 8,5 & 8 & 1,22 & 8,50 \\
\hline Classe de capacidade de uso & 8 & 9 & 6 & 7 & 7 & 7 & 7,4 & 1,14 & 7,33 \\
\hline Corredor de vegetação nativa & 8 & 10 & 6 & 9 & 10 & 10 & 8,6 & 1,67 & 9,25 \\
\hline $\begin{array}{l}\text { Densidade de drenagem dos } \\
\text { cursos d'água }\end{array}$ & 7 & 10 & 7 & 9 & 8 & 7 & 8,2 & 1,30 & 7,75 \\
\hline Vazão média & 5 & 8 & 7 & 8 & 8 & 8 & 7,2 & 1,30 & 7,75 \\
\hline Mata ciliar & 5 & 10 & 6 & 7 & 5 & 5 & 6,6 & 2,07 & 5,75 \\
\hline Diversidade de ecossistemas & 5 & 8 & 7 & 9 & 5 & 5 & 6,8 & 1,79 & 7,50 \\
\hline $\begin{array}{l}\text { Presença de Unidade de } \\
\text { Conservação (UC); }\end{array}$ & 5 & 2 & 8 & 8 & 7 & 8 & 6 & 2,55 & 7,00 \\
\hline Densidade de vegetação nativa & 1 & 9 & 6 & 8 & 5 & 5,8 & 5,8 & 3,11 & 6,33 \\
\hline $\begin{array}{l}\text { Fragmentação da vegetação } \\
\text { nativa }\end{array}$ & 7 & 9 & 4 & 8 & 5 & 6,6 & 6,6 & 2,07 & 6,67 \\
\hline $\begin{array}{l}\text { Influência da bacia para o } \\
\text { regime de cheias }\end{array}$ & 8 & 10 & 9 & 10 & 10 & 10 & 9,4 & 0,89 & 9,75 \\
\hline
\end{tabular}

TABELA 3: Matriz de pesos normalizados e valores para os critérios (Matriz Payoff).

TABLE 3: Criteria standardized weights and values (Payoff Matrix).

\begin{tabular}{l|c|c|c|c|c|c|c|c|c}
\hline \multirow{2}{*}{\multicolumn{1}{c|}{ Critério }} & \multicolumn{7}{|c|}{ Peso normalizado } & \multicolumn{7}{c}{ Valoração por bacia } \\
\cline { 2 - 10 } & $\begin{array}{c}\text { Média } \\
\text { expurgada }\end{array}$ & Moda & 1 & 2 & 3 & 4 & 5 & 6 & 7 \\
\hline Área da bacia & 0,024 & 0,011 & 3 & 1 & 3 & 3 & 3 & 3 & 5 \\
Grau de urbanização & 0,100 & 0,108 & 1 & 2 & 1 & 5 & 2 & 4 & 2 \\
Área de risco de inundação & 0,089 & 0,092 & 2 & 2 & 2 & 1 & 1 & 1 & 5 \\
Classe de Capacidade de Uso & 0,077 & 0,076 & 4 & 5 & 4 & 5 & 3 & 1 & 2 \\
Corredor de vegetação nativa & 0,097 & 0,108 & 1 & 5 & 1 & 5 & 5 & 5 & 5 \\
Densidade de drenagem dos cursos d'água & 0,081 & 0,076 & 1 & 5 & 1 & 5 & 5 & 1 & 3 \\
Vazão média & 0,081 & 0,086 & 3 & 1 & 3 & 3 & 3 & 3 & 5 \\
Mata ciliar & 0,060 & 0,054 & 5 & 5 & 5 & 5 & 5 & 1 & 3 \\
Diversidade de ecossistemas & 0,079 & 0,054 & 1 & 1 & 1 & 1 & 5 & 5 & 3 \\
Presença de Unidade de Conservação (UC); & 0,073 & 0,086 & 1 & 5 & 1 & 1 & 1 & 1 & 5 \\
Densidade de Vegetação Nativa & 0,066 & 0,068 & 3 & 1 & 5 & 3 & 5 & 5 & 5 \\
Fragmentação da vegetação nativa & 0,070 & 0,072 & 3 & 1 & 4 & 3 & 5 & 5 & 3 \\
Influência da bacia para o regime de cheias & 0,102 & 0,108 & 2 & 2 & 1 & 5 & 2 & 2 & 1 \\
\hline Total pesos normalizados & 1,000 & 1,000 & - & - & - & - & - & - & - \\
\hline
\end{tabular}

\section{Aplicação dos métodos de análise multicriterial}

Após aplicação dos dois métodos de análise multicriterial, usando-se a média (média expurgada) e a moda para tratamento dos pesos obtidos com o questionário, não se constataram diferenças entre os resultados tratados com média ou com moda, nem no método PC, nem no método CGT (Tabelas 4 e 5 ). As pequenas diferenças observadas (inferiores a 3,3\%) entre as duas medidas aplicadas, nos dois métodos, podem ser negligenciadas. 
Comparando-se os dois métodos de análise multicriterial, observa-se que não houve diferenças entre os métodos PC e CGT nas primeiras cinco colocações de bacias selecionadas (Tabela 5). A bacia 7 foi primeira colocada, seguida das bacias 4, 5, 6 e 2, na aplicação dos métodos PC e CGT. A diferença entre as duas primeiras colocações (bacias 7 e 4) foi muito pequena em ambos os métodos, nas duas medidas de tendência central. A maior diferença entre essas duas sub-bacias foi de 5,5\% no método PC, usando-se média para estimativa dos pesos, e a menor, 2,2\%, no método CGT com a moda. A obtenção de alta prioridade para a bacia 4 (córrego São Quirino) concorda com sua posição bem a montante na bacia, seu uso predominantemente rural, com baixa impermeabilização e maior fragilidade dos seus solos e a elevada densidade de cursos d'água. Todavia, a maior prioridade obtida para a bacia 7 (ribeirão das Pedras) deve ser discutida. A bacia hidrográfica 7 (ribeirão das Pedras) tem relevo menos acidentado, solos menos frágeis e elevado percentual de área urbanizada em seu alto e médio cursos. Se por um lado, a bacia 7 tem vários indicadores positivos para sua escolha e, assim, implementação do estudo de recuperação das APPs, a exemplo de sua maior extensão, elevada densidade de formações vegetais nativas, presença de UC, maior área com risco de inundação e maior vazão média, por outro lado, como é uma bacia alongada (Figura 2) e de grande extensão, estes indicadores não necessariamente ocorrem em locais próximos. Assim, apesar desta ter maior área com risco de inundação e maior vazão média, a inundação e a desembocadura deste afluente no Anhumas ocorrem no baixo curso do Anhumas, já que parte do baixo curso deste ribeirão principal foi incluída na bacia 7. Sendo essa desembocadura em seu baixo curso, não haverá influência no regime do Anhumas a montante. Ademais, grande parte da área urbanizada da bacia 7 encontra-se em seu alto e médio curso, dividindo a bacia em duas porções bem distintas, uma urbanizada, à montante, e a outra mais rural, bem à jusante. A elevada urbanização das áreas na alta e média bacias restringe a recuperação de suas APPs, de maneira que esta pode ser feita quase que somente em seu baixo curso, o que reduz o impacto benéfico das ações de recuperação. Esses aspectos destacam a maior importância de alguns indicadores, não adequadamente considerados na análise, como Grau de Urbanização, e menor importância de outros, como Área da Bacia. Infere-se, por isso, que um recurso de análise que considere a distribuição espacial desses indicadores, ou mesmo o formato da bacia, como o índice de circularidade (Christofoletti, 1980), seja importante em bacias com maiores extensões. Um recurso que teria melhorado a avaliação é a subdivisão da bacia 7 em duas, uma que abrangesse apenas o baixo curso do ribeirão das Anhumas e a outra que abrangesse apenas a bacia do ribeirão das Pedras, de suas cabeceiras até a desembocadura deste no Anhumas. Isto provavelmente alteraria os resultados da análise, já que colocaria em bacias separadas indicadores que juntos contribuíram para seleção da bacia 7. Uma sugestão oriunda da interpretação desses resultados e aplicável de maneira generalizada é que, ao proceder-se a uma análise para seleção de bacias hidrográficas para finalidades semelhantes, limite-se o tamanho das bacias separadas, de maneira a torná-las mais homogêneas. Partindo disso, pode-se concluir que a importância do indicador Área da Bacia não foi considerada adequadamente nesse trabalho. Se esse indicador (área) fosse, ao contrário do que foi feito, considerado com proporcionalidade inversa à sua importância, teria sido atenuada a heterogeneidade da distribuição de alguns indicadores. Em função disso, considera-se a bacia 4, do córrego São Quirino, como mais adequada para implementação de estudos de recuperação ambiental.

Nas demais posições (terceira a sétima), os resultados obtidos são coerentes com os indicadores das respectivas bacias hidrográficas. As bacias 5 (Baixo-Médio Anhumas) e 6 (Monte D’Este) são, na seqüência do ordenamento (Tabela 5), aquelas com menor grau de urbanização, apresentando à bacia 5 maiores valores de vulnerabilidade à erosão (solos e relevo), densidade de drenagem, número e diversidade de fragmentos e vazão média que a bacia hidrográfica 4. No ordenamento, as bacias seguintes, bacias 2 (córrego do Mato Dentro), 3 (médio Anhumas) e 1 (alto Anhumas), são aquelas mais urbanizadas, onde a recuperação ambiental em APPs seria extremamente difícil e restrita espacialmente, pelo elevado grau de impermeabilização superficial, reflexo da ocupação e infraestrutura urbanas instaladas. Mesmo assim, a sutil diferença entre as três últimas bacias reflete as pequenas diferenças entre essas. Observa-se pequena inversão nas duas últimas posições entre as bacias 1 e 3 (Tabela 5), mas como essa diferença não ultrapassou 4,3\% (método PC, pesos calculados pela média), não foi considerada relevante. 
TABELA 4: Distância $\left(l_{s}\right)$ calculada para as bacias pelos dois modelos de análise multicriterial. Ponderação obtida com uso da média e da moda.

TABLE 4: Distance $\left(l_{s}\right)$ for each basin calculated by two multicriteria analysis methods. Weights treated by mean and by mode.

\begin{tabular}{c|c|c|c|c}
\hline \multirow{2}{*}{ Bacias } & \multicolumn{2}{|c|}{ Programação de compromisso } & \multicolumn{2}{c}{ Jogos cooperativos } \\
\cline { 2 - 5 } & Média & Moda & Média & Moda \\
\hline 1 & 0,69 & 0,70 & 1,94 & 1,94 \\
2 & 0,60 & 0,58 & 2,13 & 2,20 \\
3 & 0,67 & 0,67 & 1,91 & 1,91 \\
4 & 0,36 & 0,35 & 3,00 & 3,05 \\
5 & 0,45 & 0,47 & 2,69 & 2,64 \\
6 & 0,50 & 0,50 & 2,39 & 2,40 \\
7 & 0,34 & 0,34 & 3,11 & 3,12 \\
\hline
\end{tabular}

Ressalvadas as restrições apresentadas para priorização da bacia 7 (ribeirão das Pedras), independentemente do método utilizado (PC ou CGT) e do tipo de processamento dos pesos obtidos nos questionários (média ou moda), a análise multicriterial se mostrou bastante efetiva neste processo de seleção de bacias hidrográficas quando se considera um grande número de fatores. A análise tornou o processo de seleção mais objetivo, bem como apresentou flexibilidade, o que permite a sua aplicação com diferentes objetivos ou enfoques. Deve-se ressaltar, contudo, que essa efetividade da aplicação da análise multicriterial nesse tipo de estudo depende consideravelmente dos indicadores e critérios utilizados e de como estes são aplicados. Isso ficou evidenciado na seleção da bacia 7 como prioritária.

TABELA 5: Ordenação das sub-bacias do ribeirão das Anhumas por prioridade para seleção. Ponderação obtida com o uso da média e da moda.

TABLE 5: Anhumas subasins ranked for selection priority. Weights treated by mean and by mode.

\begin{tabular}{c|c|c|c|c}
\hline \multirow{2}{*}{ Prioridade } & \multicolumn{2}{c|}{ Programação de compromisso } & \multicolumn{2}{c}{ Jogos cooperativos } \\
\cline { 2 - 5 } & Média & Moda & Média & Moda \\
\hline 1 & bacia 7 & bacia 7 & bacia 7 & bacia 7 \\
2 & bacia 4 & bacia 4 & bacia 4 & bacia 4 \\
3 & bacia 5 & bacia 5 & bacia 5 & bacia 5 \\
4 & bacia 6 & bacia 6 & bacia 6 & bacia 6 \\
5 & bacia 2 & bacia 2 & bacia 2 & bacia 2 \\
6 & bacia 3 & bacia 3 & bacia 1 & bacia 1 \\
7 & bacia 1 & bacia 1 & bacia 3 & bacia 3 \\
\hline
\end{tabular}

Por fim, pode-se dizer que aspectos importantes a considerar nesse tipo de análise são (a) evitar critérios com sobreposição, ou seja, critérios que no todo ou em parte possam representar o mesmo indicador; (b) realizar adequado julgamento de valor para os critérios, evitando, por exemplo, que critérios cuja presença ou aumento deva ser considerado como de influência negativa, o seja de maneira positiva, ou vice-versa; (c) selecionar critérios de natureza diversa, como por exemplo, sociais ou econômicos, além daqueles ambientais utilizados neste estudo; (d) usar a experiência do tomador de decisão como complementar aos resultados obtidos com os especialistas. 


\section{CONCLUSÕES}

Apesar da inversão da ordem de prioridade nas duas últimas posições (menos prioritárias) entre as bacias 1 e 3 quando se aplicaram os dois métodos de análise multicriterial, PC e CGT, esses métodos, bem como o tratamento dos pesos pela média ou pela moda, não mostraram diferenças relevantes na seleção de bacias prioritárias.

O critério Área da Bacia foi considerado pelos especialistas de pequena importância para seleção de bacias-piloto e seu uso redundou em distorções na análise, a exemplo da seleção da bacia 7 (ribeirão das Pedras) como prioritária.

A análise multicriterial foi efetiva na seleção de bacias hidrográficas para recuperação de APPs, permitindo o uso de vários fatores com flexibilidade. Apesar dessa objetividade, a interferência do tomador de decisão se mostrou importante para corrigir distorções na análise.

A ordenação das bacias prioritárias para recuperação de APPs, após interferência do tomador de decisão foi $4>7>5>6>2>3>1$.

\section{AGRADECIMENTO}

À Fundação de Amparo à Pesquisa do Estado de São Paulo (FAPESP), pelo suporte financeiro (Processo n. 01/02952-1).

\section{REFERÊNCIAS BIBLIOGRÁFICAS}

BRASIL. Lei Federal no 4771/65, de 15 de setembro de 1965, alterada pela Medida Provisória nº 2.166-67, de 24 de agosto de 2001. Brasília, DF: Congresso Nacional, 2001.

BRIGUENTI, E.C. Geoindicadores na avaliação da qualidade ambiental da Bacia do Ribeirão das Anhumas, Campinas, SP. 2005. 129f. Dissertação (Mestrado) - Universidade de Campinas, Campinas, SP, 2005.

CAMPINAS. Secretaria Municipal de Planejamento, Desenvolvimento Urbano e Meio Ambiente. Mapas: bacias hidrográficas. Disponível em: <http://www.campinas.sp.gov.br/seplama/mapas/hidro.htm.> Acesso em: 04 de abr. 2005.

CEPAGRI. Centro de Pesquisas Meteorológicas e Climáticas Aplicadas à Agricultura. Universidade Estadual de Campinas Clima de Campinas. Disponível em $<\underline{\text { http://www.cpa.unicamp.br/outras-informacoes/clima-de- }}$ campinas.html.> Acesso em 05 set. 2007.

CHRISTOFOLETTI, A. Geomorfologia. 2.ed. São Paulo: Edgard Blücher, 1980. 188 p.

CULLEN J.R.L.; BELTRAME, T.P.; PÁDUA, C.V.; PÁDUA, S.M. Trampolins ecológicos e zonas de benefício múltiplo: ferramentas agroflorestais para a conservação de paisagens rurais fragmentadas na Floresta Atlântica brasileira. Natureza e Conservação, vol. 1, n. 1, p. 37-46, 2003.

EMBRAPA. Centro Nacional de Pesquisa de Solos. Sistema Brasileiro de Classificação de Solos. Brasília : Embrapa Produção de Informação; Rio de Janeiro : Embrapa Solos, 1999. 412 p.

GERSHON, M.; DUCKSTEIN, L. Multiobjective approaches to river basin planning. Journal of Water Planning and Management, v. 109, n.1, p.13-28, 1983.

INSTITUTO GEOLÓGICO. Subsídios do meio físico-geológico ao planejamento do município de Campinas (SP). São Paulo: Secretaria do Meio Ambiente do Estado de São Paulo, 1993. 217 p. Mapas de escala 1:50.000.

KAGEYAMA, P.; GANDARA, F.B.; OLIVEIRA, R.E. Diversidade e restauração da floresta tropical. In: KAGEYAMA, P.; GANDARA, F.B.; OLIVEIRA, R.E. (org.) Restauração ecológica de ecossistemas naturais. Botucatu: FEPAF, 2003. p. 27-48.

KRONKA, FRANCISCO J.N.; NALON, M.A.; MATSUKUMA, C.K. Inventário da vegetação natural do Estado de São Paulo. (Atlas) São Paulo: Secretaria do Meio Ambiente/Instituto Florestal, 2005. 200 p.

LEPSCH, I.F. (coord.) Manual para levantamento utilitário do meio físico e classificação de terras no sistema de capacidade de uso. $4^{\text {a }}$ Aproximação. Campinas : Sociedade Brasileira de Ciência do Solo, 1983. 175p.

METZGER, J.P. Como restaurar a conectividade de paisagens fragmentadas? In: KAGEYAMA, P.; GANDARA, F.B.; OLIVEIRA, R.E. (org.) Restauração ecológica de ecossistemas naturais. Botucatu: FEPAF, 2003. p. 49-76.

PARDALOS, P.M.; SISKOS, Y; ZOPOUNIDIS, C. (Eds.) Advances in multicriteria analysis. (Non-convex optimization and its application. v.5). Dordrecht, Netherlands: Kluwer, 1995. 249 p. 
SÃo PAUlO. Atlas das Unidades de Conservação Ambiental do Estado de São Paulo. São Paulo: Secretaria de Estado do Meio Ambiente, 2000.

SÃO PAULO. Secretaria de Economia e Planejamento. Plano cartográfico do estado de São Paulo: Cartas topográficas, escala 1:10.000. São Paulo: Instituto Geográfico e Cartográfico, 2005.

SANTIN, D.A. A vegetação remanescente do município de Campinas (SP): mapeamento, caracterização fisionômica e florística visando a conservação. 1999. 467f. Tese (Doutorado) - Universidade de Campinas, Campinas, SP, 1999.

SÃO PAULO. Secretaria do Meio Ambiente. Sistema Integrado de Gerenciamento de Recursos Hídricos do Estado de São Paulo (SIGRH): Regionalização Hidrológica. Disponível em: $<$ http://www.sigrh.sp.gov.br/cgi-bin/regnet.exe. $>$ Acesso em: 07 de out. 2005.

TORRES, R.B., NOGUEIRA, F.A.; COSTA, M.C. \& PERES Filho, A. (Org.). Recuperação ambiental, participação e poder público: uma experiência em Campinas, SP. Projeto de Pesquisa em Políticas Públicas. Processo Fapesp no. 01/02952-1. Relatório de pesquisa 2006. Disponível em: <http://www.iac.sp.gov.br/ProjetoAnhumas/> Acesso em: 02 fev. 2006.

TUCCI, C.E.M. (Org.). Hidrologia: ciência e aplicação. 2.ed. rev. Porto Alegre: Ed. da Universidade Federal do Rio Grande do Sul ; São Paulo: EDUSP, 1993. 943 p. (coleção ABRH, vol. 4)

ZUFFO, A.C.; REIS, L.F.R.; SANTOS, R.F.; CHAUDHRY, F.H. Aplicação de métodos multicriteriais ao planejamento dos recursos hídricos. Rev. Bras. Rec. Hídricos, v.7, n.1, p. 81-102, 2002.

ZELENY, M. Multiple criteria decision making. New York: McGraw-Hill, 1982. 563 p. 